\title{
COMPORTAMENTO DE BEBÊS EM SITUAÇÕES DE SEPARAÇÃO E REENCONTRO COM OS PAIS, NA ROTINA DIÁRIA DA CRECHE ${ }^{1}$
}

\author{
Lígia Ebner Melchiori ${ }^{2}$ \\ Zélia Maria Mendes Biasoli Alves
}

\begin{abstract}
RESUMO: Esse trabalho teve por objetivo verificar como é o comportamento dos bebês e adultos no momento de separação e reencontro em uma creche do interior paulista. Os dados foram obtidos através de entrevista semi-estruturada com 21 educadoras de creche, individualmente entrevistadas, sobre cada bebê de 4 a 24 meses sob seus cuidados $(n=71)$ e através da observação gravada em vídeo da situação de separação e reencontro entre pais-bebês. Os dados obtidos foram analisados de forma quantitativa, quantitativa-interpretativa e qualitativa. Os resultados desse estudo parecem indicar que essa amostra de bebês tem uma forte ligação com a figura materna, evidenciada principalmente depois dos oito meses em diante, com possibilidades de ser um apego seguro em função da manifestação de alegria quando as mães retornam e da afetividade demonstrada por elas; isto leva a afirmação de que o fato de o bebê permanecer no ambiente coletivo durante o dia não estaria afetando o seu vínculo afetivo com a mãe.
\end{abstract}

Palavras chaves: comportamento de bebês; vínculo afetivo mãe-bebê; creche

\section{THE BEHAVIOR OF BABIES ON THE ROUTINE OF A DAY CARE CENTER: SEPARATION AND MEETING}

\begin{abstract}
This paper aims to verify how do babies and adults behave at the moment when they meet and separate at a day-care-center. Data were obtained from individual interviews following a semi-structured guide with 21 educators of the day-care-center about each from 4 to 24 months under their care $(n=90)$ and from the videotape records of the situations. Data were analyzed through a quantitative system, quantitativeinterpretative and qualitative one. The results of this study indicate that this sample of babies has a strong link with mother, especially after they were eight month old. This finding suggests a secure attachment pattern because they manifest a lot of joy when their mothers come back and they are very affective with them. So, collective setting is not affecting, in a negative way, babies/mothers attachment.
\end{abstract}

Key words: babies behavior, mother-child attachment, day-care center

Os estudos do vínculo mãe-bebê, quando estes freqüentam a creche, têm obtido resultados controversos. Na revisão de Belsky e Steinberg (1978), eles não encontraram evidências conclusivas de que o ambiente coletivo prejudica a ligação mãe-criança. Já no estudo de 1988, Belsky mostrou que a freqüência dos bebês na creche por mais de 20 horas semanais durante o primeiro ano de vida poderia interromper o processo de apego, aumentando o risco do

\footnotetext{
' Artigo recebido para publicação em setembro de 2000; aceito em novembro de 2000

2Endereço para Correspondência: Lígia Ebner Melchiori, Departamento de Psicologia, UNESP. Av. Luís Edmundo Carrijo Coube $\mathbf{s} / \mathbf{n}$ - Vargem Limpa Bauru - Cep 17001-970 - e-mail: melch@novonet.com.br
}

Paidéia, FFCLRP-USP, Rib. Preto, jan/julho/2000. desenvolvimento de problemas psicológicos. Em outro trabalho, Belsky e Rovine (1988) relataram que $43 \%$ dos bebês que passam 20 ou mais horas por semana na creche estabelecem um vínculo de apego inseguro com a mãe, contra $26 \%$ dos que permanecem por menos de 20 horas semanais. Clark-Stewart (1989) encontrou um nível similar de significância dessa associação: $36 \%$ de apego inseguro para bebês com períodos mais extensivos na creche e $29 \%$ dos que passam períodos menores.

Os dados da pesquisa de Barglow, Vaughn \& Molitor (1987) vão nesta mesma direção, e eles discutem a ligação da creche com alta taxa de apego inseguro, principalmente do tipo evitador, vivenciadas 
por experiências diárias de bebês que sọfrem algum grau de rejeição materna.

Entretanto, resultados de outros estudos apontam para outra direção. Rubenstein e Howes (1979) mostraram que a separação diária não produz efeitos negativos na ligação de apego mãe-bebê. E, mais recentemente, Roggman, Langlois, Hubbs-Tait e Rieser-Danner (1994) denunciaram que nas pesquisas publicadas a respeito de apego e creche, ocorre o "file drawer problem", inicialmente proposto por Rosenthal (1979). Eles revelam que, nessa área, há inúmeros estudos não publicados porque apresentavam correlação nula entre apego e a permanência da criança na creche. Para esses autores o problema estaria em que os pesquisadores relutam em submeter para publicação dados que não apresentam diferença significativa, e que os editores tendem a aceitar somente estudos que rejeitam hipóteses nulas, pondo de lado os fracassos nas replicações. Esse procedimento aumenta a probabilidade de que se encontrem revisões afirmando existir uma relação entre o tipo de apego e a permanência na creche, uma vez que o material publicado disponível fortalece a hipótese pretendida. A partir daí pode-se, de uma forma artificial, propagar falsas generalizações, que têm implicações em diversos níveis: teórico, comportamental e político.

Esses autores replicaram quatro estudos apresentados por Belsky (1988) utilizando amostras similares, a mesma medida de avaliação do apego, definição de cuidado extenso na creche ou não e análise técnica dos dados. Nenhum resultado foi forte $o$ suficiente para mostrar a relação significativa entre o apego inseguro e a permanência por um longo período semanal na creche.

Para dirimir inúmeras dúvidas a respeito de vários aspectos controversos, NICHD (1997) fez um extenso estudo longitudinal, com uma amostra de mais de 1000 pares mães-bebês, de diversas raças e estruturas familiares, vivendo em nove estados diferentes dos EUA, Os bebês foram identificados no nascimento e acompanhados até os três anos de idade. Além disso, eles também examinaram o contexto das creches.

O importante é salientar que NICHD (1997) não encontrou nenhuma evidência de que o apego inseguro estava ligado a maior quantidade de horas que a criança passa na creche. Eles obtiveram dados comprovando que crianças que desenvolvem o ape- go seguro têm mães mais sensíveis e responsivas e um ajustamento psicológico positivo. Os resultados desse estudo indicam claramente que a creche por ela mesma não constitui nem risco nem benefício para o desenvolvimento do apego mãe-bebê, tal como avaliado pela Situação Estranha.

Em um outro recente estudo longitudinal (NICHD, 1998), os pesquisadores concluíram que, quando os preditores familiares são positivos, o desenvolvimento sócio-emocional e cognitivo das crianças não é afetado pelo cuidado externo em tenra idade, mesmo se vivenciado por grande parte do dia e começando nos primeiros meses de vida. Esses dados são consistentes com os de Clarke-Stewart, Gruber e Fitzgerald (conforme citado por NICHD, 1998). Isso não implica minimizar a importância das condições do ambiente coletivo, que, de fato, também exercem influência no desenvolvimento das crianças sob seus cuidados, como colocam Phillips, McCartney e Scarr (1987), salientando que sua qualidade global afeta muitos aspectos da competência social e ajustamento da criança.

A situação de separação e reencontro pais/ criança quando estas freqüentam a creche, pode ser um forte indicativo de como são as relações entre essa díade ou tríade. Em função de todas essas considerações, o objetivo desse estudo foi o de descrever como é o comportamento dos bebês e dos adultos na separação e reencontro em uma creche localizada em cidade do interior de São Paulo.

\section{Método}

\section{Sujeitos}

Os sujeitos foram 71 bebês de quatro a 24 meses, 35 do sexo feminino (49\%) e 36 do sexo masculino $(51 \%)$ que freqüentavam o Centro de Convivência Infantil (C.C.I.), filhos de funcionárias do Hospital das Clínicas cujo nível de escolaridade das mães variou do primeiro grau ao superior e as profissões incluíam de faxineira do hospital a médicas e administradoras e 21 educadoras, com idades de 21 a 57 anos, e de três a 18 anos de experiência no cuidado de bebês no C.C.I. O nível de escolaridade mínimo exigido nessa função é o primeiro grau completo e $24 \%$ das educadoras se enquadravam nele. Mais da metade tinha o segundo grau completo $(57 \%)$ e o restante (19\%) incompleto. 


\section{Procedimento de Coleta de Dados}

Para atingir os objetivos propostos, buscouse uma abordagem metodológica capaz de permitir uma coleta ampla de informações, optando-se por duas estratégias: Entrevista e Observação registrada em Vídeo.

As entrevistas semi-estruturadas foram realizadas pela pesquisadora, durante o período de trabalho das educadoras, em local separado. Elas tiveram uma duração média de 15 minutos, totalizando 21 horas de gravação.

A observação foi utilizada como estratégia de coleta de dados complementar aos obtidos através das entrevistas, com o objetivo de registrar o que acontece nessas duas atividades rotineiras na creche. A duração média das gravações foi de aproximadamente dez minutos por situação em cada um dos cinco berçários, perfazendo um total de uma hora e quarenta minutos de gravação.

\section{Procedimento de Análise de Dados}

Alguns dados foram obtidos diretamente da entrevista, pois a leitura fornecia a unidade de análise, e ela foi passada para quadros que permitiram a construção de tabelas que deram origem às figuras de porcentagem de ocorrência, em função das variáveis sexo e idade do bebê (análise quantitativa).

Para aprofundar a análise de alguns aspectos, foi necessário fazer uma análise quantitativa/ interpretativa (Biasoli Alves, 1998), construindo-se sistemas de categorias para o relato das educadoras, obedecendo aos seguintes critérios: o de Exaustividade, o de Exclusividade, o Nivel de Amplitude das Categorias e o Nível de Inferência das Categorias (Sigolo \& Biasoli-Alves, 1998).

Foi incluída também uma análise qualitativa (Biasoli Alves, 1998) buscando, nos relatos dos educadores, informações que pudessem reforçar alguns pontos, esclarecer ou ilustrar outros, adotandose o procedimento de colocar frases retiradas diretamente das entrevistas.

\section{Resultados}

\section{Chegada à Creche}

Segundo o relato das educadoras, os bebês geralmente chegam à creche, trazidos pela mãe: isso ocorre com $100 \%$ dos femininos e $96 \%$ dos masculi- nos; há uma porcentagem pequena que conta com o acompanhamento do pai. As educadoras relatam que o comportamento mais comum dos pais, nessa hora, é expressar afetividade para com os bebês (em tomo de $92 \%$ para ambos os sexos).

Nos dados da filmagem, $100 \%$ das mães demonstraram afeto com o bebê nesse momento: beijaram, conversaram e agradaram a sua cabecinha. As educadoras receberam os bebês falando com eles e rindo, conversando com a mãe para saber se estava tudo bem.

A descrição das educadoras permitiu identificar oito maneiras diferentes de os bebês se comportarem quando chegam ou são colocados dentro do berçário: (a) riem ou sorriem para a educadora; (b) abrem os braços para ela; (c) andam ou correm para dentro do berçário; (d) abraçam e beijam-na; (e) mantêm-se quietos; (f) choram; (g) seguram-se na mãe ou no pai; (h) resmungam. Esses comportamentos foram agrupados em quatro categorias: "Aceitação da Educadora" quando eles riem ou sorriem, abrem os braços e abraçam e beijam a educadora; "Aceitação do Ambiente/Independência do Bebê" quando eles andam ou correm para dentro do berçário; "Condição Neutra" quando mantêm-se quietos na hora de entrar no berçário; "Protesto" se choram, se seguram na mãe ou no pai, resmungam. Como houve relatos de bebês que eram citados ora emitindo comportamentos pertencentes a uma das categorias ora a outras, eles foram postos em um grupo à parte, denominado "Não Definido". Os resultados aparecem na Figura 01.

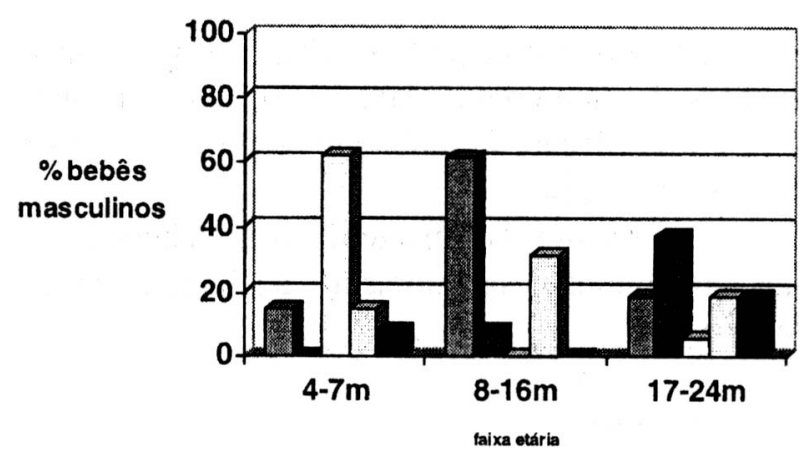




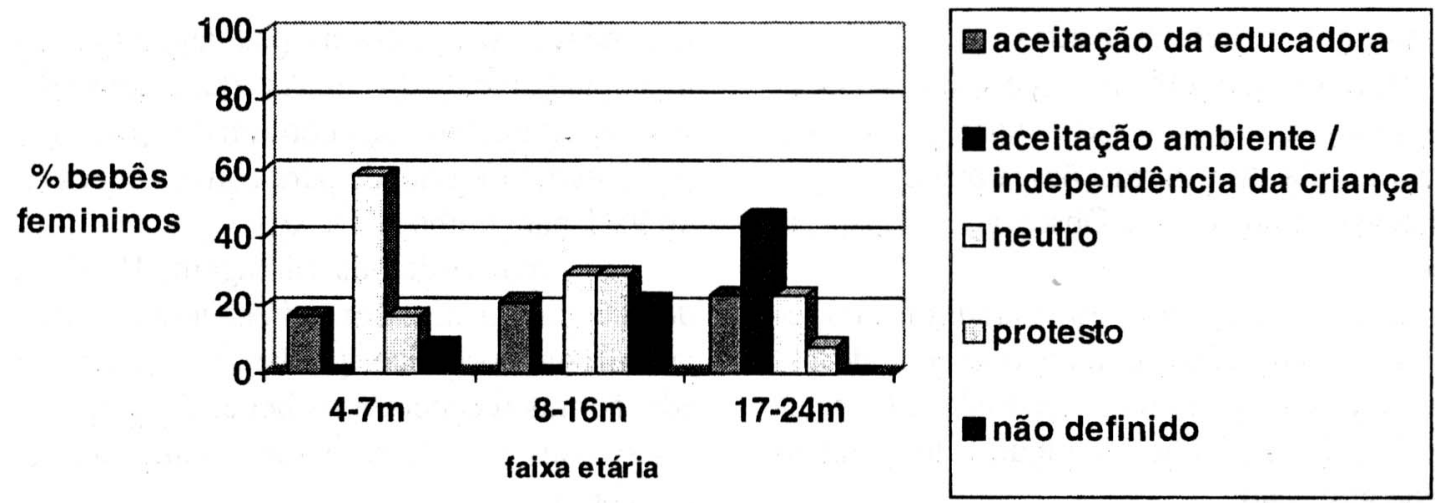

Figura 01: Proporção de ocorrência das categorias de reações à chegada à creche, de bebês, em função do sexo e da faixa-etária.

A figura evidencia, em um primeiro momento, a semelhança entre os comportamentos dos bebês de 4 a 7 meses, de ambos os sexos, ao chegarem na creche: cerca de $60 \%$ está na categoria Neutro. Na faixa etária seguinte, há diferenças e semelhanças no comportamento dos bebês de cada sexo: sobressai para os meninos a aceitação da educadora (sorriem para ela, abrem os braços ou a abraçam e beijam) e para as meninas há variedade (mantêm-se quietas e protestam ao adentrar na creche, através de choro e resmungos). Observa-se também que, nessa faixa etária, ocorre o maior percentual da categoria de Comportamentos de Protestos para ambos os sexos. De 17 a 24 meses o mais evidente é a independência dos bebês: "andam/correm para dentro do berçário". Bebês masculinos dessa faixa etária também protestam mais que os femininos.

Analisando as categorias ao longo das diferentes faixas etárias pode-se observar que a neutralidade diminui com a idade, o protesto é inconstante e a aceitação do ambiente tende a ser maior para os mais velhos.

Os dados da filmagem mostram bebês calmos e tranqüilos nesse momento, aceitando a troca do colo.

\section{Saída da Creche}

Pelo relato das educadoras, são as mães que buscam os bebês na creche na maioria das vezes ( $87 \%$ meninas e $84 \%$ meninos), raramente acompanhadas pelos maridos. Os pais assumem esta tarefa em menos de $20 \%$ das vezes e é importante assinalar que isto ocorre apenas quando eles são um pouco mais velhos.

De acordo com as educadoras, $100 \%$ das mães/ pais de bebês do sexo masculino e $95 \%$ dos femininos expressam afetividade quando buscam seus filhos na creche. A observação comprova esses dados.

Os bebês costumam agir na hora do reencontro de diversas formas: (a) se aconchegam no colo da mãe ou pai; (b) riem ou sorriem para a mãe/pai ou ambos; (c) se atiram no colo ou estendem os braços para os pais; (d) engatinham, andam, correm em direção aos pais; (e) emitem sons, falam, conversam com os pais; (f) ficam agitados; (g) mantêm-se quietos; (h) choram. Esses comportamentos foram agrupados em duas categorias: Aceitação do Retorno dos Pais e Demonstração de Neutralidade na situação.

Exprimem "Aceitação do Retorno da Mãe/ Pai" comportamentos de se aconchegarem no colo deles, rirem, jogarem ou darem beijos e abraça-los, engatinharem, andarem/correrem na direção deles, conversarem com eles, se atirarem em seus braços ou estenderem os braços em sua direção:

"Nossa, a hora que ele vê a mäe é aquela festa né de mãe e filho, ela já chega fazendo folia lá na porta e ele fica todo, todo, se a gente tiver com ele no colo tem que tomar cuidado, ele se agita tanto que a gente corre o risco de ir os dois pro chão".

Quando o bebê fica agitado ao ver a mãe/ pai ou chora, também foi colocado na categoria de

Paidéia, FFCLRP-USP, Rib. Preto, jan/julho/2000. 
Aceitação do Retorno deles, pois, segundo as educadoras, esses comportamentos exprimem apego aos pais:

"Se ela vê a mãe na janela ela já chora, começa a chorar e ela vai chorando pra mãe. tem medo que a gente não vai entregar".
O comportamento foi categorizado como Neutro quando a criança mantém-se quieta, tranqüila.

A Figura 02 apresenta o percentual de bebês que se comportam demonstrando Aceitação dos Pais quando estes vão buscá-los ou mantendo-se Neutros, em função da faixa etária e do sexo.
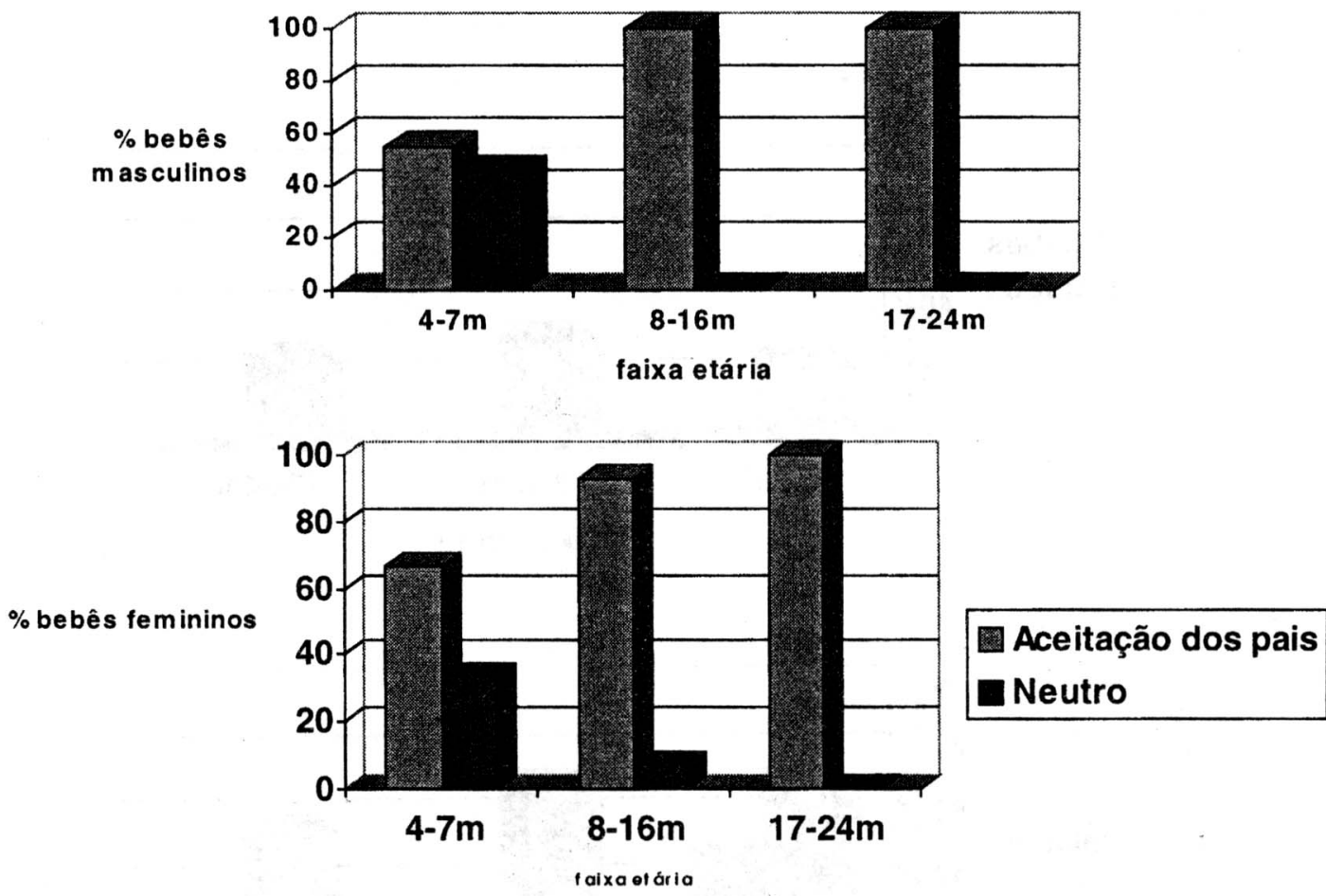

Figura 02: Proporção de ocorrência de reações dos bebês ao contato com os pais, na saída da creche.

A figura mostra que há semelhanças no comportamento dos bebês de ambos os sexos, quanto à proporção de ocorrência de cada uma das categorias em diferentes faixas etárias. Bebês de 4 a 7 meses, na visão das educadoras, já demonstram aceitação dos pais, apesar de que $45 \%$ dos meninos e $33 \%$ das meninas mantêm-se Neutros nessa hora. Nas duas faixas etárias seguintes, a grande maioria demonstra aceitação dos pais.

Os dados da filmagem mostram que as mães com bebês no Berçário 1 são as que agem de forma menos efusiva e também seus filhos tendem a ficar calmos/tranqüilos na passagem-do colo da educadora para o delas. Do Berçário 2 em diante, todos os bebês ${ }^{3}$ demonstram reconhecer a figura materna/paterna: riem, sacodem os braços e as pernas, estendem os braços para serem pegos, emitem sons e, quando já caminham, andam na direção deles.

Paidéia, FFCLRP-USP, Rib. Preto, jan/julho/2000.

\section{O Humor na Chegada e na Saída}

Outro aspecto avaliado quando da chegada e saída da creche foi o humor dos bebês. Esses dados estão colocados lado a lado visando facilitar uma comparação desses dois momentos. $\mathrm{O}$ humor foi categorizado como: irritado/intranqüilo, calmo/tranqüilo ou alegre/feliz. A irritação/intranquuilidade ocorre quando o bebê chega chorando, resmungando:

"A mãe vem trazendo, a hora que ela vê que tá chegando no berçário ela já começa a querer chorar né, ai a mãe já traz ela no colo, entrega, a gente recebe ela no colo e ela tá chorando".

\footnotetext{
'A exceção ocorreu com um bebê que foi retirado do berço onde estava dormindơ e passado para o colo do pai, que não conseguiu esconder o orgulho ao pegar o filho, abrindo um largo sorriso em direção à câmera de filmagem.
} 
O estado é de calma e tranqüilidade quando o bebê aceita a troca de colo:

"Ele chega bem cedo, mas ele entra tranquiilo, numa boa, vem para o colo da gente sem reclamar, quietinho, ele entra tranquiilo".

O bebê é considerado alegre/feliz pela educadora quando:
"Ela muda de colo numa boa, ela é super dada, ela aceita muito bem a gente, até se joga no colo da gente, ela é ótima, já chega alegre".

Na Figura 03 encontram-se os dados sobre humor dos bebês do sexo masculino quando chegam e saem da creche.

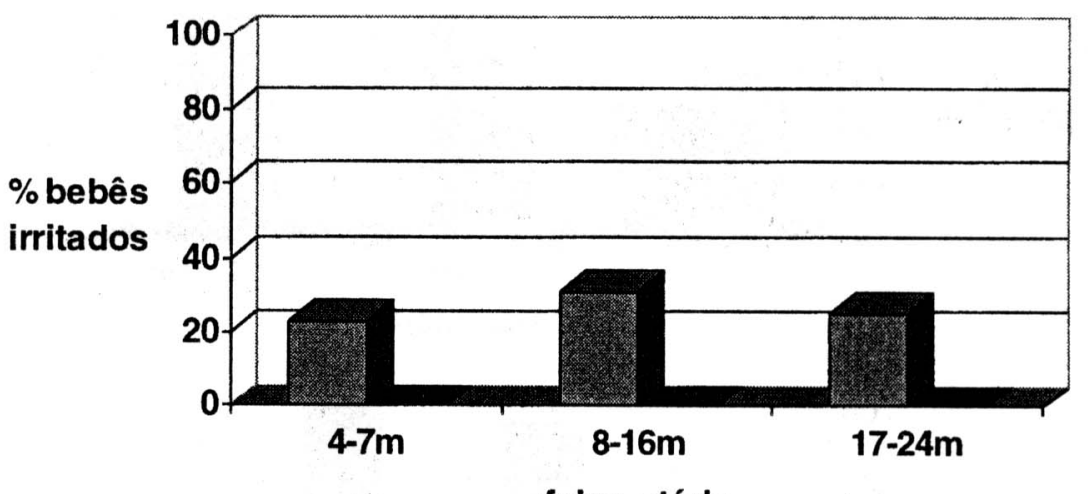

faixa etária
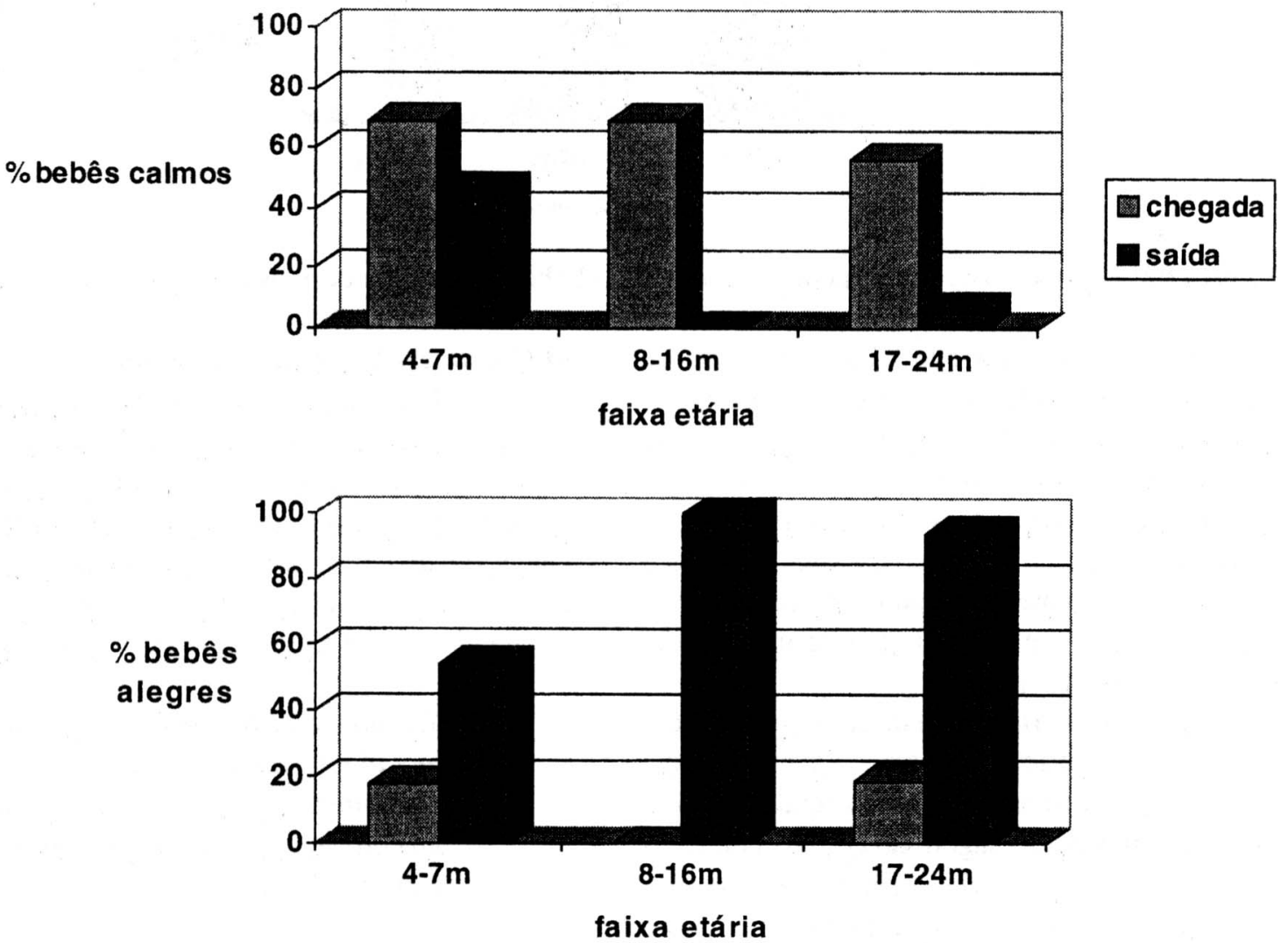

Figura 03: Proporção de bebês do sexo masculino que se apresentam irritados/intranqüilos, calmos/tranqüilos ou alegres/felizes quando da chegada e da saída da creche, em função da faixa etária. 
Fica evidente uma forte tendência de manifestar alegria ao sair da creche em todas as faixas etárias, apesar de o percentual ser menor para os mais novos. No geral, a maioria dos bebês entra calmo/ tranqüilo na creche e sai manifestando alegria e felicidade.

A Figura 04 traz os dados referentes aos bebês do sexo feminino.
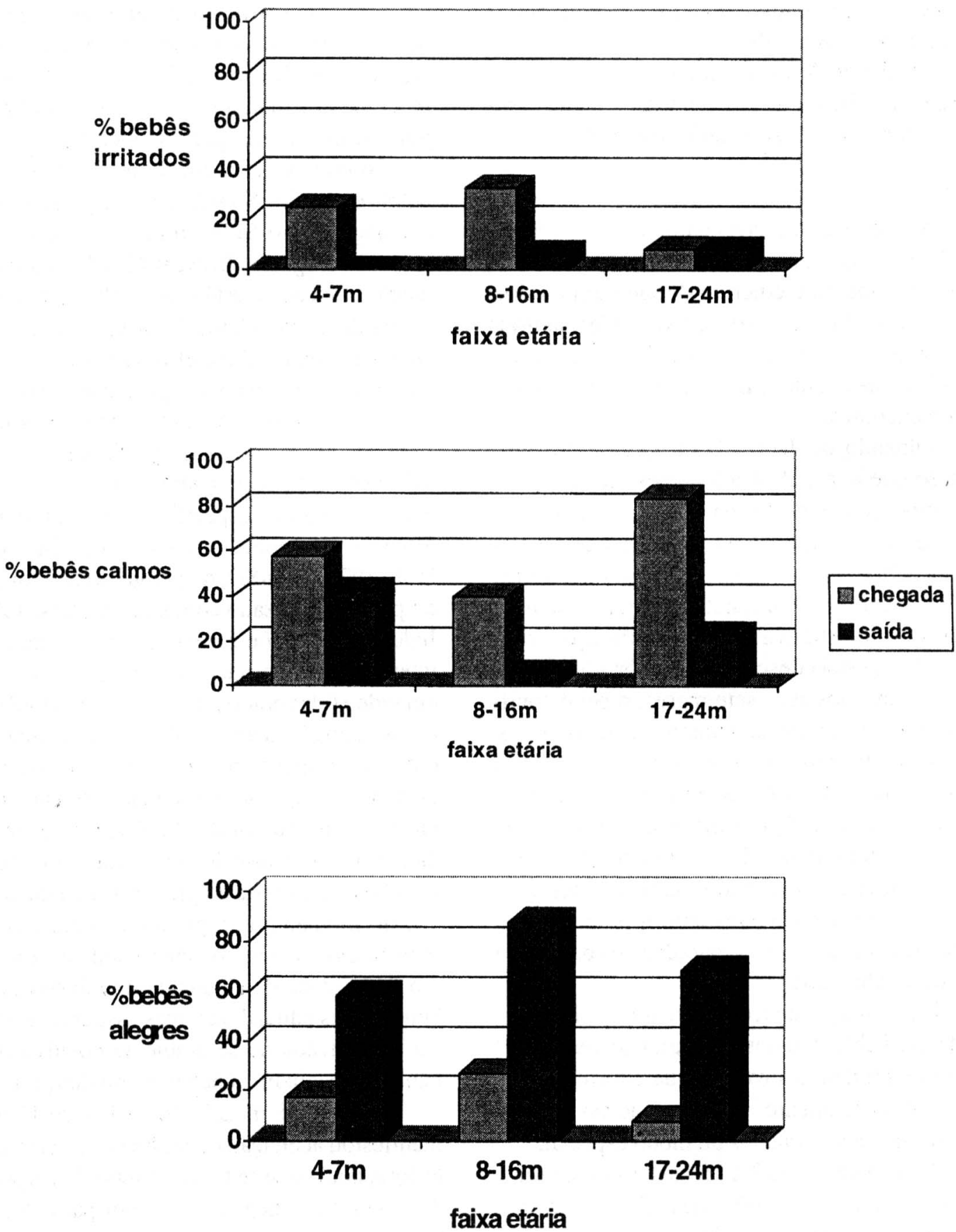

Figura 04. Proporção de bebês do sexo feminino que se apresentam irritados/intranqüilos, calmos/ tranqüilos ou alegres/felizes quando da chegada e da saída da creche em função da faixa etária. 
Pode-se verificar que entre bebês do sexo feminino também ocorre uma evidente manifestação de alegria/felicidade no reencontro com os pais. No geral, mais da metade chega à creche calma/tranquiila e sai alegre/feliz. A irritação/intranqüilidade ocorre para menos da metade dos bebês nas duas faixas etárias iniciais e a manifestação desse estado na saída aparece com percentuais baixos (a freqüência é de um entre todos os bebês).

Os dados de observação referentes à chegada e saída dos bebês da creche, indicam que essas situações ocorrem de forma muito tranqüila.

\section{Discussão}

Muito se tem escrito na literatura a respeito da influência da separação mãe-bebê quando este freqüenta um ambiente coletivo durante um ou dois períodos do dia. Pode-se partir de situações naturais e obter algum subsídio para a análise desse tema, verificando o que acontece nos momentos da separação e do reencontro.

Olhando os dados da chegada e da saída encontra-se que bebês de 4 a 7 meses, de ambos os sexos, comportam-se de forma semelhante. Na chegada, o que mais se destaca é a neutralidade, predominando a calma/tranquiilidade. E, na saída o sorrir/ rir para a mãe/pai e o ficar quieto, mantendo-se neutro. Esses dados mostram grandes aproximações com o que Bowlby (1984) descreve. O autor afirma que em torno dos três aos seis, sete meses, o bebê continua a se comportar de forma amistosa com as pessoas, como vinha fazendo de modo crescente desde o nascimento, mas o faz de maneira um pouco mais acentuada para com a figura materna, a relação de apego não está totalmente desenvolvida, não existe uma pessoa que tenha se tornado sua "base segura", e, de outro, os bebês ainda não manifestam nenhuma ansiedade especial ao serem separados dos pais, nem medo de desconhecidos.

Já na situação de reencontro no C.C.I., quando metade dos bebês demonstra alegria ao ver a mãe/ pai, tem-se os primeiros sinais de que a formação da relação está em andamento, uma vez que esses adultos são identificados e tratados de modo especial.

A faixa etária de 8 a 16 meses parece ser a de maiores mudanças. Bebês masculinos aceitam mais a educadora - sorriem, abrem os braços para

\footnotetext{
4 Figura em quem a criança se apoia para explorar o ambiente ou para verificar a possibilidade ou năo de perigo.
}

elas, abraçam ou beijam - do que os femininos. No entanto, bebês de ambos os sexos também emitem sinais de protestos nessa hora. $\mathrm{Na}$ saída do C.C.I., a maioria mostra aceitação dos pais no seu retorno e, de forma expressiva - riem/sorriem, engatinham ou andam em sua direção, emitem sons ou conversam com os pais. A situação de Saída da Creche, gravada em vídeo, evidencia a manifestação de alegria dos bebês ao verem a mãe (riem, batem os braços, as pernas, vão rápido em sua direção). $\mathrm{O}$ humor predominante na chegada ao C.C.I. é a calma/tranqüilidade para os meninos e, para as meninas, ainda que com padrão menos definido, sobressai o humor positivo: calma e alegria. Na saída, a categoria mais frequuente é a alegria/felicidade para os dois sexos.

Segundo Bowlby (1984), nessa etapa geralmente o apego já está desenvolvido e o bebê age de forma diferente: Como é capaz de se locomover, vai atrás da mãe, recebe-a efusivamente quando regressa e utiliza-a como a base segura para suas explorações.

É importante enfatizar que nesse estudo não se pretendeu avaliar o apego diretamente, nem com a mãe nem com a educadora, até porque para fazê-lo existem métodos específicos, tais como a análise da Situação Desconhecida (Ainsworth, Blehar, Waters \& Wall, 1978), o Q-Set, questionário que foi desenvolvido para ser utilizado com pais (Waters, 1997), o Care Index, que propõe formas de análise de situações de interação de brincadeiras entre mãe-criança gravadas em vídeo (elaborado por Crittenden, 1988). No entanto, os dados indicam possibilidade de maior estabelecimento de apego entre mãe-bebê do que entre educadora-bebê, o que se infere pela diferença no comportamento e no humor dos bebês ao chegarem e saírem da creche. A análise do vídeo indica que mesmo quando o bebê manifesta alegria ao ver a educadora, a reação no momento em que a mãe chega geralmente é mais intensa. Contudo, não se pode deixar de levantar a possibilidade de alguns desenvolverem apego também com as educadoras, mas essa interação parece ficar prejudicada nesse ambiente coletivo porque elas não acompanham os bebês na mudança de berçário ${ }^{5}$.

Quase metade dos bebês de 17 a 24 meses manifestou aceitação do ambiente da creche e da educadora, ainda que se tenha observado certa frequiência de protesto na chegada (mais por parte dos meninos). Por outro lado, bebês femininos apresentam maior

\footnotetext{
"Alualmente isso foi modificado, as mesmas educadoras acompanham os bebês desde o momento de entrada no C.C.I., até saírem do berçário.

Paidéia, FFCLRP-USP, Rib. Preto, jan/julho/2000.
} 
percentual de comportamentos neutros e a ocorrência de comportamentos que denotam irritação/ intranqüilidade é praticamente nula. Isto sugere uma adaptação mais tranqüila á situação. Contudo, outros estudos se fazem necessários para abordar essa possível diferença de gênero quanto às reações de bebês à chegada à creche.

Os resultados das análises levadas a efeito nesse estudo, assim como os de NICHD (1998), parecem indicar que essa amostra de bebês tem uma forte ligação com a figura materna, principalmente dos 8 meses em diante, sugerindo um padrão de apego seguro, a partir da manifestação de alegria quando as mães retornam e da afetividade demonstrada por elas. Pode-se dizer que o fato de o bebê permanecer no ambiente coletivo durante o dia não está afetando o seu vínculo com a mãe.

Apesar de esse estudo não ter sido planejado para analisar o apego, os dados trazem fortes indicações da existência desse vínculo com a figura materna; outrossim, o estado de calma/tranqüilidade demonstrado pelos bebês ao chegarem à creche e a alegria/felicidade manifestada na saída parecem indicar que eles aprenderam a conviver nesses dois ambientes de forma harmoniosa, tendo noção desse ir e vir, dessa troca diária de ambiente e das pessoas que deles cuidam.

\section{Referências Bibliográficas}

Ainsworth, M.D.S.; Blehar, M.; Waters, E. \& Wall, S. (1978). Patterns of attachment: a pychological study of the strange situation. Hillsdale: Lawrence Erlbaum Associates.

Barglow, P.; Vaughn, B. \& Molitor, N. (1987). Effects of maternal absence due to employment on the quality of infant-mother attachment in a low-risk sample. Child Development, 58, 945-954.

Belsky, J. (1988). The "effects" on infant day-care reconsidered. Early Childhood Research Quartely, 3, 235-272.

Belsky, J. \& Rovine, M. (1988). Nonmaternal care in the first year of life and security on infant parent attachment. Child Development, 59, 157-167.

Belsky, J. \& Steinberg, L. (1978). The effects of daycare: a critical review. Child Development, 49, 929-949.

Biasoli-Alves, Z.M.M. (1998). A Pesquisa em Psi-

Paidéia, FFCLRP-USP, Rib. Preto, jan/julho/2000. cologia - análise de métodos e estratégias na construção de um conhecimento que se pretende científico. Em G. Romanelli \& Z.M.M. BiasoliAlves (Orgs.), Diálogos Metodológicos sobre Prática de Pesquisa (pp. 135-157). Ribeirão Preto: Legis Summa.

Bowlby, J. (1984). Apego. (A. Cabral, Trad) São Paulo: Martins Fontes (Trabalho original publicado em 1969).

Clarke-Stewart, K.A. (1989). Infant day care: maligned or malignant? American Psychologist, 44, 266-273.

Crittenden, P. (1988). Relationships at risk. Em J. Belsky \& T. Nezworski (Eds.), The Clinical Implications of Attachment (pp. 136-174). Hillsdale: Lawrence Erlbaum Associates.

NICHD Early Child Care Research Network (1997). The effects of infant child care on infant-mother attachment security: results of the NICHD study of early child care. Child Development, 68, 860-879.

NICHD Early Child Care Research Network (1998). Relations between family predictors and child outcomes: are they weaker for children in child care? Developmental Psychology, 34, 1119-1128.

Phillips, D., McCartney, K. \& Scarr, S. (1987). Child care quality and children's social development. Developmental Psychology, 23, 537-543.

Roggman, L.A.; Langlois, J.H.; Hubbs-Tait, L. \& Rieser-Danner, L.A. (1994). Infant day care attachment, and the "file drawer problem". Child Development, 65, 1429-1443.

Rosenthal, R. (1979). The "file drawer problem" and tolerance for null results. Psychological Bulletin, $86,638-641$.

Rubenstein, J.L. \& Howes, C. (1979). Caregiving and infant behavior in day care and in home. Developmental Psychology, 15, 1-24.

Sigolo, S.R.R.L. \& Biasoli-Alves, Z.M.M. (1998). Análise de dados de interação mãe-criança - construção de sistemas de categorias. Em G. Romanelli \& Z.M.M. Biasoli-Alves (Orgs.), Diálogos Metodológicos sobre Prática de Pesquisa (pp. 87118).Ribeirão Preto: Legis Summa.

Waters, E. (1997). Attachment Behavior Q-Set (Version 3) [on line]. Dept. Psychology, SUNY Stony Brook, MN.Y. 11794 (email: everett.waters@sunysb.edu). 